Seminar Nasional Teknologi Informasi dan Kedirgantaraan (SENATIK)

Vol. II, 26 November 2016, ISSN: 2528-1666

\title{
KAJIAN KONFIGURASI PESAWAT TEMPUR GENERASI 4 DAN GENERASI 5
}

\author{
Ika Suwarni \\ Sekolah Tinggi Teknologi Adisutjipto Yogyakarta. \\ Jl Janti Blok R Lanud Adisutipto, Yogyakarta \\ E-mail: ika.soe22@gmail.com
}

\begin{abstract}
Fighter role is very important for air defense of a State. Until 2016, the fighter who is still being developed fourth generation and fifth generation fighter. there is no basic standard in the classification generation fighter aircraft. In this study, will be evaluating of fighter technology of fourth generation and fifth generation fighterof the configuration aspect. Based on the configuration and design goals, there were marked differences between the fourth and fifth generation. Studies in the literature data only in the form of printed and electronic articles are public domain data. Part studied in fighter are nose, wing, fuselage, tail, engine and weapon configurations. The design goal of fifth generation fighter concept is low Radar Cross Section (RCS). The low RCS design concept implementation of the internal weapon bay, blended wing body, internal fuel tank, low observable inlet, and the use of radar absorbent material in the composite. Therefore each aircraft that does not have these characteristics, it is included in the fourth generation.
\end{abstract}

Keywords: Fighter, fourth generation, fifth generation, Radar Cross Section

\section{Pendahuluan}

Negara yang kuat adalah negara yang mampu mempertahankan kedaulatan dari segala bentuk ancaman dan pelanggaran, dengan demikian kekuatan sistem pertahanan menjadi salah satu acuan kekuatan suatu negara. Frederick Hartmann dalam bukunya "The Relations of Nations" menuliskan bahwa salah satu elemenyang membuat sebuah negara kuat atau lemah adalah kemampuan militernya, meliputi jumlah dan kemampuan personel, serta jenis persenjataan yang dimiliki[1]. Semakin kuat, canggih, efektif dan efisien persenjataan atau alutsista yang dimiliki suatu negara, menunjukkan semakin kuat pula sistem pertahanannya.

Ancaman pertahanan dapat masuk melalui darat, laut maupun udara. Dari sisi matra udara, peran pesawat sangat dibutuhkan sebagai pengawalan. Setiap pesawat yang melanggar wilayah udara suatu negara, terlebih dahulu akan diperingatkan untuk meninggalkan wilayah tersebut. Peringatan melalui komunikasi tidak dimungkinkan karena tidak diketahuinya frekuensi dari pesawat pelanggar, sehingga salah satu cara yang tepat yaitu dengan mengirimkan pesawat tempur untuk melakukan pengejaran dan peringatan terhadap pesawat pelanggar. Tentunya pesawat yang digunakan harus mempunyai kemampuan pengejaran atau intercept.

Dalam penelitian ini akan dikaji perkembangan teknologi pesawat tempur yang ada di dunia dilihat dari aspek konfigurasi. Hingga tahun 2016, pesawat tempur yang masih dikembangkan adalah pesawat tempur generasi ke 4 dan generasi 5. Sejauh ini penulis belum menemukan adanya jurnal maupun penelitian yang menjelaskan perbedaan dari kedua generasi tersebut.

Pada dasarnya penggolongan generasi pada pesawat tempur belum mempunyai standar yang baku, maka dengan penelitian ini dimaksudkan untuk mendapatkan perbedaan yang jelas antara generasi 4 dengan generasi 5 dalam segi konfigurasinya.

\section{Metode Penelitian}

Kajian yang dilakukan hanya bersumber pada data kepustakaan berupa artikel cetak maupun elektronik yang merupakan data public domain. 


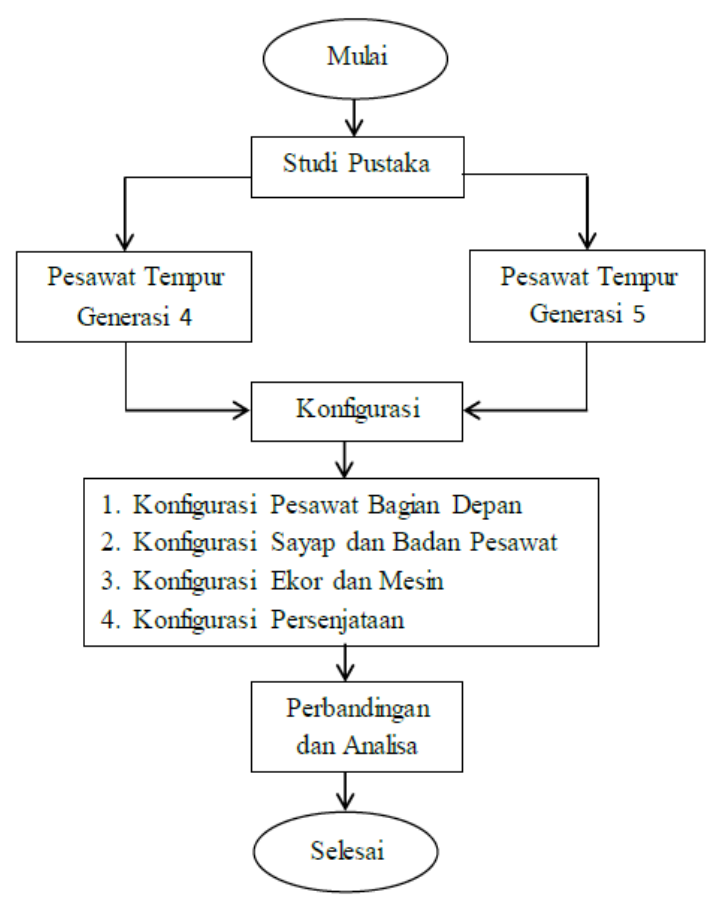

Gambar 1. Alur Penelitian

Bagian yang dikaji dalam konfigurasi pesawat tempur generasi 4 dan 5 adalah konfigurasi depan atau nose, konfigurasi sayap dan fuselage, konfigurasi ekor dan mesin, serta konfigurasi persenjataan.

\section{Kajian Pesawat Tempur}

Hingga tahun 2016, pesawat tempur yang masih banyak digunakan dan dikembangkan di Dunia adalah pesawat generasi 4 dan generasi 5.Tabel 1 menunjukkan jenis pesawat tempur yang diklaim termasuk dalam generasi 4 dan 5 berdasarkan data public domain :

Tabel 1. Pesawat Tempur Generasi 4 dan 5

\begin{tabular}{|c|c|c|c|}
\hline Negara & Generasi 4 & $\begin{array}{c}\text { Generasi } \\
4,5\end{array}$ & Generasi 5 \\
\hline \multirow[t]{4}{*}{$\begin{array}{l}\text { United } \\
\text { States }\end{array}$} & $\begin{array}{l}\text { F-14 } \\
\text { Tomcat }\end{array}$ & \multirow[t]{4}{*}{-} & F-22 Raptor \\
\hline & F-15 Eagle & & \multirow{3}{*}{$\begin{array}{l}\text { F-35 } \\
\text { Lightning II }\end{array}$} \\
\hline & $\begin{array}{l}\text { F-16 } \\
\text { Fighting } \\
\text { Falcon } \\
\end{array}$ & & \\
\hline & $\begin{array}{l}\text { F/A-18 } \\
\text { Hornet }\end{array}$ & & \\
\hline
\end{tabular}

\begin{tabular}{|c|c|c|c|}
\hline \multicolumn{4}{|c|}{ lanjutan Tabel 1.} \\
\hline Negara & Generasi 4 & $\begin{array}{c}\text { Generasi } \\
4,5\end{array}$ & Generasi 5 \\
\hline \multirow[t]{6}{*}{ Russia } & \begin{tabular}{|l|} 
Mikoyan \\
MiG-29 \\
\end{tabular} & \begin{tabular}{|l|} 
Sukhoi \\
Su-34
\end{tabular} & \multirow{2}{*}{$\begin{array}{l}\text { Sukhoi } \\
\text { PAK-FA } \\
\text { T-50 }\end{array}$} \\
\hline & \begin{tabular}{|l|} 
Mikoyan \\
MiG-31
\end{tabular} & \begin{tabular}{|l|} 
Sukhoi \\
Su-35
\end{tabular} & \\
\hline & \begin{tabular}{|l|} 
Mikoyan \\
MiG-35
\end{tabular} & & \multirow{4}{*}{$\begin{array}{l}\text { HAL-FGFA } \\
\text { (Fifth } \\
\text { generation } \\
\text { Fighter } \\
\text { Aircraft) }+ \\
\text { India }\end{array}$} \\
\hline & \begin{tabular}{|l|} 
Sukhoi \\
Su-27
\end{tabular} & & \\
\hline & $\begin{array}{l}\text { Sukhoi } \\
\text { Su-30 }\end{array}$ & & \\
\hline & $\begin{array}{l}\text { Sukhoi } \\
\text { Su-33 (AL) }\end{array}$ & & \\
\hline France & $\begin{array}{l}\text { Dassault } \\
\text { Mirage } \\
2000\end{array}$ & \begin{tabular}{|l} 
Dassault \\
Rafale
\end{tabular} & - \\
\hline $\begin{array}{l}\text { UK, } \\
\text { Germany, } \\
\text { Italy, } \\
\text { Spain }\end{array}$ & \begin{tabular}{|l|} 
Panavia \\
Tornado
\end{tabular} & $\begin{array}{l}\text { Eurofighter } \\
\text { Typhoon }\end{array}$ & - \\
\hline Sweden & - & \begin{tabular}{|l|} 
Saab Jas 39 \\
Gripen
\end{tabular} & - \\
\hline \multirow[t]{2}{*}{ China } & $\begin{array}{l}\text { Chengdu } \\
\text { J-10 }\end{array}$ & \multirow[t]{2}{*}{$\begin{array}{l}\text { Senyang } \\
\mathrm{J}-15\end{array}$} & \multirow[t]{2}{*}{$\begin{array}{l}\text { Chengdu } \\
\mathrm{J}-20\end{array}$} \\
\hline & $\begin{array}{l}\text { Shenyang } \\
\text { J-11 }\end{array}$ & & \\
\hline India & HAL Tejas & - & AMCA \\
\hline Pakistan & \begin{tabular}{|l} 
JF-17 \\
Thunder
\end{tabular} & - & - \\
\hline \multirow{2}{*}{$\begin{array}{l}\text { South } \\
\text { Korea }\end{array}$} & KAI FA-50 & \multirow[t]{2}{*}{-} & \multirow{2}{*}{$\begin{array}{l}\text { KF-X/IF-X } \\
\text { (+Indonesia) }\end{array}$} \\
\hline & $\begin{array}{l}\text { T-50 } \\
\text { Golden } \\
\text { Eagle }\end{array}$ & & \\
\hline Jepang & - & $\begin{array}{l}\text { Mitsubishi } \\
\text { F-2 }\end{array}$ & ATD-X \\
\hline
\end{tabular}

Sukhoi Su-34, Su-35, Rafale, Eurofighter Typhoon, JAS 39 Gripen, J-15, serta F-5 diklaim sebagai generasi 4,5 atau 4+ dikarenakan mengalami peningkatan performace dari pesawat sebelumnya, baik dari segi mesin, avionik, maupun penggunaan AESA radar. Pesawat-pesawat tersebut dikenalkan sejak awal tahun 2000.

\section{Hasil dan Pembahasan}

Pada dasarnya penggolongan generasi pada pesawat tempur belum mempunyai standar yang 
baku, namun jika dilihat dari konfigurasi dan sasaran perancangan, terdapat perbedaan yang kentara antara generasi 4 dengan generasi 5 .

\subsection{Konfigurasi Pesawat Bagian Depan}

Tinjauan konfigurasi pesawat bagian depan meliputi : pemasangan canard, forebody fuselage dan duct path air inlet.

\subsubsection{Canard}

Terdapat perbedaan dalam penggunaan canard pada generasi 4 dan 5.Pesawat tempur generasi 5 didominasi tanpa menggunakan canard.

Tabel 2. Perbedaan pemasangan canard pada pesawat tempur geneasi 4 dan 5

\begin{tabular}{|c|c|}
\hline Generasi 4 dan 4+ & Generasi 5 \\
\hline $\begin{array}{l}\text { Beberapa pesawat } \\
\text { (selain pesawat } \\
\text { Amerika) menggunakan } \\
\text { canard, contoh : Su-33, } \\
\text { Su-34, Su-35, Typhoon, } \\
\text { Rafale, Saab } 39 \text { Gripen }\end{array}$ & $\begin{array}{l}\text { Semua pesawat } \\
\text { yang in service tidak } \\
\text { menggunakan canard, } \\
\text { kecuali konsep chengdu } \\
\text { J-20 yang masih dalam } \\
\text { pengembangan }\end{array}$ \\
\hline
\end{tabular}
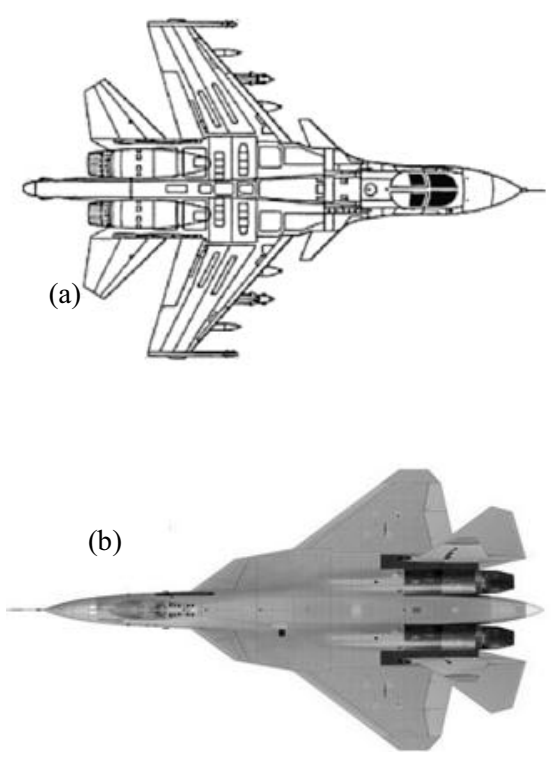

Gambar 2. Pemasangan Canard pada Su-34(a) dan PAK-FA(b)
Secara performance, canard memberikan kelebihan bermanuver, akan tetapi dalam segi navigasi penggunaan canard menyebabkan pesawat mudah terdeteksi oleh pesawat lain. Bentuk canard yang bersudut runcing membuat gelombang yang mengenai bagian tersebut mudah untuk dipantulkan kembali ke arah transmitter atau pengirim, sehingga tidak sesuai dengan konsep low radar cross section.

\subsubsection{Forebody Fuselage}

Konfigurasi fuselagebagian depan pada pesawat tempur dinamakan forebody.

Tabel 3. Konfigurasi forebody pesawat tempur geneasi 4 dan 5

\begin{tabular}{|l|l|}
\hline Generasi 4 dan 4+ & Generasi 5 \\
\hline $\begin{array}{l}\text { Bagian depan (forebody) } \\
\text { belum berbentuk chine. }\end{array}$ & $\begin{array}{l}\text { Bagian forebody dibuat } \\
\text { Chine type cross section. }\end{array}$ \\
\hline $\begin{array}{l}\text { sudutLeading Edge } \\
\text { Root Extension(LERX) } \\
\text { meyerupai } 90^{\circ} \text { dan ada } \\
\text { yang sudutnya sangat } \\
\text { kecil sehingga dapat } \\
\text { dikatakan tidak ada } \\
\text { LERX. }\end{array}$ & $\begin{array}{l}\text { terdapat leading edge } \\
\text { tertentu. }\end{array}$ \\
\hline
\end{tabular}

Chine type cross section, yaitu bentuk nose yang dibuat lancip atau runcing di ujungnya, memberi kesan ada pemisah antara bagian atas dan bawah hidung pesawat. Pemilihan bentuk Chine type cross section padaforebody bertujuan untuk menciptakan vortex, semakin lancip sudut bagian depan pesawat maka vortex yang dihasilkan semakin kuat sehingga tidak akan pecah, karena jika vortex pecah saat melewati permukaan pesawat akan menyebabkan $\mathrm{C}_{\mathrm{L}}$ lemah yang dapat berakibat stall, selain itu adanya perancangan leading edge extensiondengan sudut tertentu, dimaksudkan agar pesawat tempur dapat melakukan manuver sampai dengan sudut serang yang tinggi atau sampai dengan 25 derajat. Bahkan guna mendapatkan manuver yang bagus, leading edge extension pada PAK-FA dapat digerakkan. 


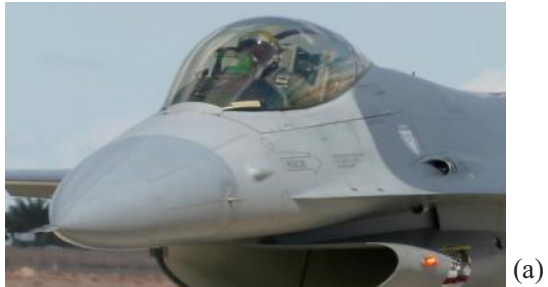

(b)

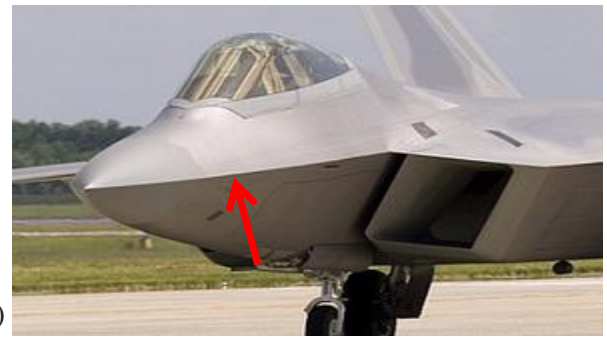

Gambar 3. Forebody pada F-16(a) dan F-22(b)

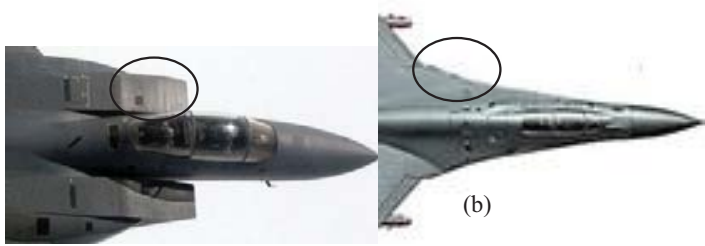

(a)

(c)

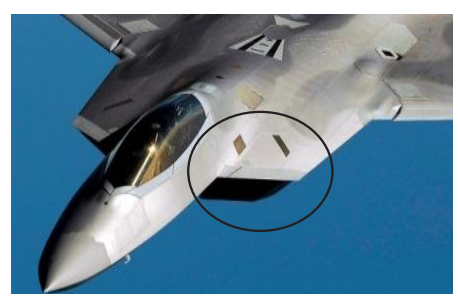

Gambar 4. Leading edge extension pesawat F-15(a) ; $\mathrm{Su}-30$ (b); F-22(c)

\subsubsection{Duct path air inlet}

merupakan bentuk penampang atau tempat yang dilalui udara saat akan masuk ke mesin (air inlet).Gambar 5 dan 6 menunjukkan bentuk duct path air inlet pada pesawat tempur generasi 4 dan 5. Dari gambar tersebut dapat dilihat bahwa bentuk duct path air inlet pada generasi 4 dan 5 mempunyai perbedaan dari segi bentuk.

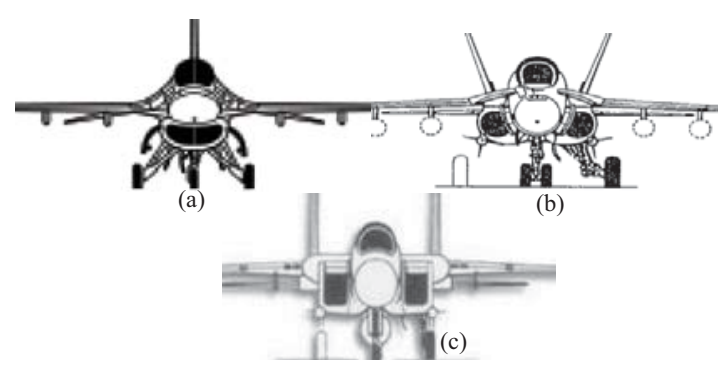

Gambar 5. Duct path air inlet pesawat generasi 4, F-16(a) ; F-18(b) ; F-15(c)
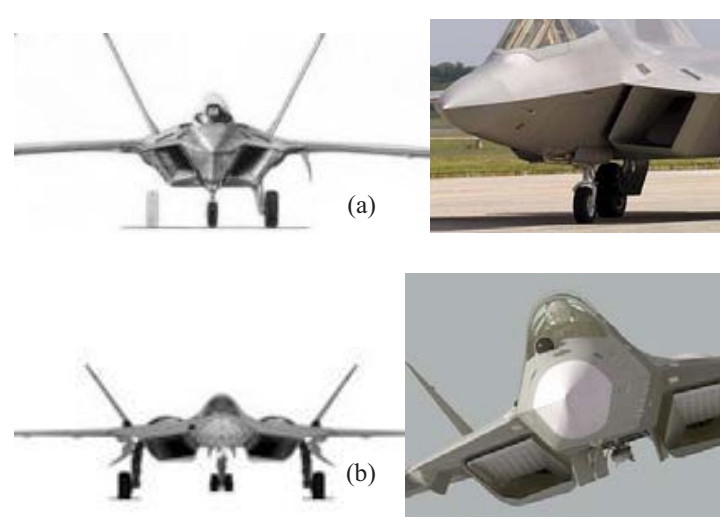

Gambar 6. Duct path air inlet pesawat generasi 5, F-22(a); AK-FA(b)

Tabel 4. Konfigurasiduct path air inlet pesawat tempur geneasi 4 dan 5

\begin{tabular}{|l|l|}
\hline \multicolumn{1}{|c|}{ Generasi 4 dan 4+ } & \multicolumn{1}{c|}{ Generasi 5 } \\
\hline $\begin{array}{l}\text { Duct path-nya masih } \\
\text { berbentuk persegi } \\
\text { dan ada pula yang }\end{array}$ & $\begin{array}{l}\text { Bentuk air intake dibuat } \\
\text { seperti jajar genjang } \\
\text { bulat, serta arah }\end{array}$ \\
“engkungannya masih & pada Air Inlet Sytem \\
dibuat melengkung \\
enderung lurus menuju \\
engine & agar pergerakan \\
& enginecompressor tidak \\
& terlihat dari luar \\
\hline
\end{tabular}

Perancangan duct path air inlet yang dibuat menyerupai jajar genjang dan melengkung, dimaksudkan agar pergerakanenginecompressor tidak terlihat dari luar. Konsep low observable inletini bertujuan untuk mereduksi Radar 
Cross Section (RCS), karena jika gelombang radar lawan mengenai fan compressor yang berputar, maka gelombang tersebut akan terpantul kuat menuju transmitter-nya, namun jika duct tersebut dibuat melengkung dan mesinnya tidak terlihat, maka gelombang radar akan mengenai dinding dan terpantul lemah menuju transmitternya. Perancangan duct yang seperti ini juga mempunyai kerugian, yaitu thrust yang dihasilkan akan berkurang, selain itu pembuatan duct path yang melengkung akan membutuhkan banyak ruang.

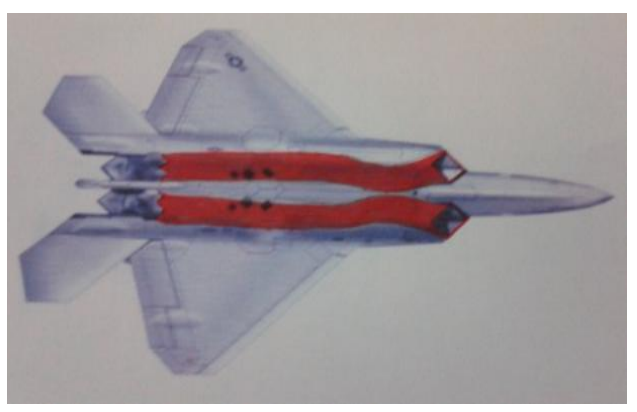

(a)

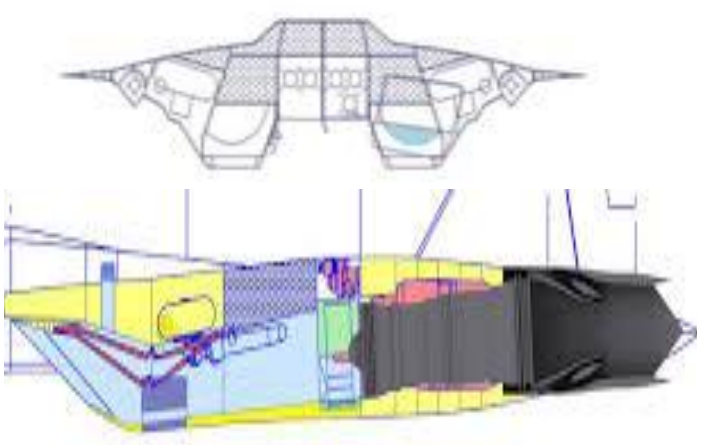

(b)

Gambar 7. Arah lengkungan duct-path air inlet pesawat tempur generasi 5, F-22(a) ; PAK-FA(b) [2]

\subsection{Konfigurasi Sayap dan Badan Pesawat}

Seluruh pesawat tempur generasi 4 dan 5 menggunakan konfigurasi sayap delta.Dari segi aerodinamis, sayap delta memberikan keuntungan maneuverability. Sedangkan dari segi structural, sayap delta lebih kuat dan kaku saat pesawat melakukan manuver, di samping keuntungan manufakturnya yang lebih sederhana.

Sayap delta juga memiliki karakteristik stall yang baik. Pada pesawat subsonik yang menggunakan konfigurasi sayap konvensional seperti pesawat transport, biasanya mengalami stall pada sudut serang $15^{\circ}$ atau $20^{\circ}$, sedangkan pada pesawat bersayap delta, sudut stall dapat mencapai $35^{\circ}$. Oleh karena itu, sayap delta sangat cocok digunakan untuk pesawat supersonik, seperti pesawat tempur.

Bentuk sayap yang menyatu dengan badan pesawat (fuselage) disebut dengan blended wing body. Permukaan pesawat terlihat lebih smooth tanpa banyak lekukan yang diakibatkan karena bentuk sayap dan badan pesawat. Blended wing body bertujuan untuk memberikan manuver dan aerodinamika yang baik serta mampu mereduksi Radar Cross Section.

Tabel 5. Konfigurasi sayap dan badan pesawat tempur geneasi 4 dan 5

\begin{tabular}{|l|l|}
\hline \multicolumn{1}{|c|}{ Generasi 4 dan 4+ } & \multicolumn{1}{|c|}{ Generasi 5 } \\
\hline Delta wing & Delta wing \\
\hline $\begin{array}{l}\text { Pesawat dibentuk } \\
\text { dari sudut-sudut } \\
\text { yang beragam. } \\
\text { Blended wing body dengan } \\
\text { sudut yang seragam seperti } \\
\text { di leading edge extension, } \\
\text { leading edge sayap, HTP } \\
\text { dan VTP. }\end{array}$ \\
\hline Contoh : F-15
\end{tabular}

Secara umum pesawat generasi 5 dirancang dengan sudut-sudut yang seragam. Sudut pada leading edge sayap, horizontal tailplane dan vertical tailplane dibuat sama besarnya, tujuannya adalah agar gelombang atau berkas radar yang dipantulkan tidak saling bertabrakan, sehingga tidak menyebabkan berkas kembali ke transmitter. Konsep ini sesuai dengan low radar cross sections. 


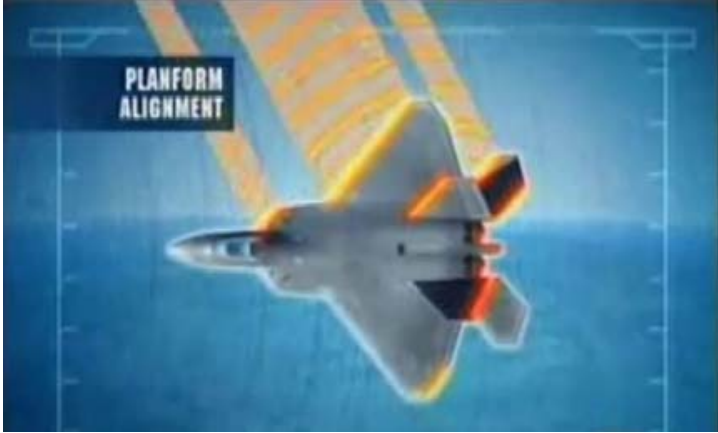

Gambar 8. Pemantulan gelombangpada sudut-sudut yang sama[3]

\subsection{Konfigurasi Ekor dan Mesin}

\subsubsection{Ekor}

Konfigurasi ekor atau tail, meliputi :horizontal tailplane (HTP) dan vertical tailplane (VTP). Terdapat dua Vertical Tail Plane (VTP) pada generasi 5 dimaksudkan untuk melindungi engine dari radar cross section. VTP yang dirancang miring keluar atau disebut canted out bertujuan untuk mendapatkan manuver yang lebih bagus dibandingkan VTP lurus ke atas yang banyak terdapat di generasi 4.Sementara itu, pada HTP dirangcang all moving, yaitu slat dan flap dapat bergerak otomatis. Tujuannya adalah untuk memberikan kelincahan (agility), karena pesawat harus mampu secepat mungkin menciptakan momen untuk bermanuver.

Tabel 6. Konfigurasi ekor (tail) pesawat tempur geneasi 4 dan 5

\begin{tabular}{|l|l|}
\hline Generasi 4 dan 4+ & Generasi 5 \\
\hline $\begin{array}{l}\text { Masih ada yang } \\
\text { menggunakan single }\end{array}$ & $\begin{array}{l}\text { Terdapat double VTP } \\
\text { dengan Pemasangan } \\
\text { VTP dimiringkan keluar } \\
\text { atau canted out }\end{array}$ \\
\hline $\begin{array}{l}\text { Sebagian besar HTP } \\
\text { belum all moving }\end{array}$ & HTP bersifat all moving \\
\hline
\end{tabular}

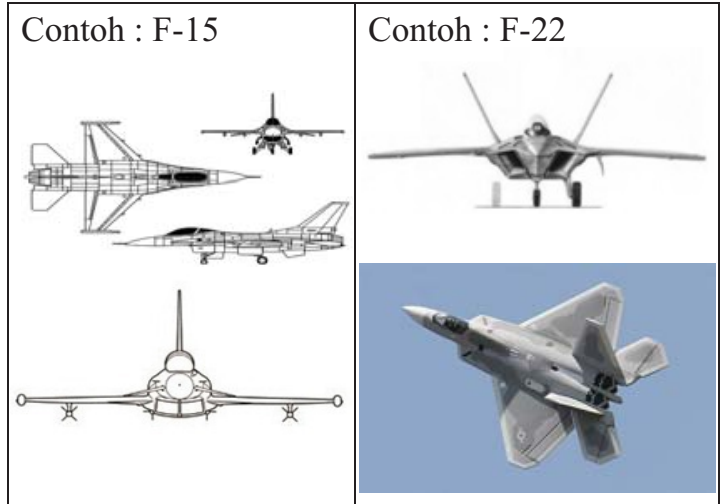

\subsubsection{Mesin}

Semua pesawat tempur generasi 5 menggunakan dua teknologi yang diterapkan pada mesinnya, yaitu kemampuan engine dalam melakukan supercruise dan pemasangan thrust vectoring pada engine untuk mendukung maneuverability pesawat tempur. Dalam perkembangannya generasi 4, khususnya 4+ juga telah menggunakan dua teknologi tersebut.

Dengan adanya kemampuan supercruise pada engine, menyebabkan pesawat tempur tersebut dapat terbang pada kecepatan supersonik tanpa menggunakan afterburner. Afterburner merupakan penghasil panas yang tinggi dan mudah ditangkap oleh infrared maupun radar. Oleh karena itu, untuk meminimalkan RCS dan untuk tetap mendapatkan kecepatan yang tinggi untuk mengejar atau menghindar lawan, maka pesawat tempur perlu menerapkan kemampuan supercruise. Teknologi supercruise diterapkan untuk menghasilkan kecepatan yang besar dengan bahan bakar yang tidak terlalu banyak, sehingga dapat menghemat konsumsi bahan bakar.

Guna mendukung maneuverability, maka pada engine dipasang thrust vectoring, yaitu adanya kemampuan thrust untuk memberikan arah pesawat dengan bantuan defleksi alat yang dipasang di exhaust engine. Thrust vectoring berfungsi sebagai pengendali pada saat kecepatan rendah, yang dimana saat itu bidang kendali tidak berfungsi efektif. Misalnya pada saat spin, bidang kendali pesawat tempur pada saat itu tidak berfungsi dan thrust vectoring sebagai pengendali satu-satunya untuk recovery spin, sehingga dapat mencegah terjadinya stall. 
Berdasarkan gerakannya,thrust vectoring dibagi menjadi dua yaitu 2 Dimensi dan 3 Dimensi. Kemampuan thrust vectoring 2D meliputi gerakan pitch atau yaw, sedangkan thrust vectoring 3D meliputi gerakan pith atau yaw, dan roll.
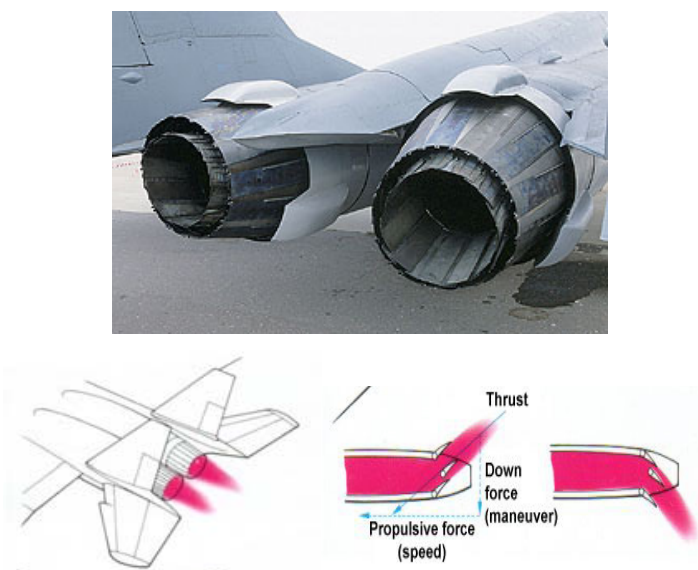

Gambar 9. Thrust Vectoring pada pesawat PAK-FA $[4,5]$

Hanya beberapa pesawat tempur generasi 4 yang telah menggunakan teknologi supercruise dan thrust vectoring. Rusia lebih antusias untuk mengembangkan teknologi supercruise dan thrust vectoring pada pesawat tempurnya. Disisi lain, Eropa lebih konsentrasi mengembangkan kemampuan supercruise pada engine mereka, namun melihat dari kemampuan negara-negara tersebur tidak menutup kemungkinan untuk mengembangkan thrust vectoring, seperti pada Eurofighter Typhoon. Sementara itu untuk pengembangan pesawat tempur generasi 4, Amerika lebih memilih mengembangkan teknologi tersebut pada pesawat experiment dan research, seperti pengembangan thrust vectoring pada F-15 STOL/MTD, F-15 ACTIVE, F-16 VISTA, F-18 HARV dan pengembangan supercruise pada F-16XL.

Berbeda dengan generasi 4, rata-rata pesawat tempur pada generasi 5 telah dilengkapi thrust vectoring dan kemampuan supercruise. F-35 saat ini dalam tahap uji produksi mengembangkan thrust vectoring untuk varian F-35B (STOVL). F-35 juga tidak mempunyai kemampuan supercruise, walaupun begitu F-35 mampu mempertahankan Mach1.2 untuk melesat sejauh150 milesatau sekitar $241 \mathrm{~km}$ tanpa menggunakan fuel-gulping afterburners $[6,7]$.
Tabel 7. Kemampuan mesin pesawat tempur geneasi 4 dan 5

\begin{tabular}{|l|l|}
\hline \multicolumn{1}{|c|}{ Generasi 4 dan 4+ } & \multicolumn{1}{|c|}{ Generasi 5 } \\
\hline Beberapa pesawat & Hampir keseluruhan \\
sudah menggunakan & pesawat telah \\
thrust vectoring, & menggunakan thrust \\
dan berkemampuan & vectoring dan mempunyai \\
supercruise, seperti & kemampuan supercruise, \\
: Su-30, Typhoon. & kecuali F-35. \\
\hline
\end{tabular}

Generasi 5 juga didominasi Penggunaan Twin Enginepada pesawat tempurnya, hal ini bertujuan untuk meningkatkan keandalan saat berkelahi atau combat, karena jika satu engine fail masih ada back-up untuk mengkaver pesawat tempur saat di udara, misalnya untuk bermanuver. Selain itu twin engine juga dibutuhkan untuk menyuplai kebutuhan kelistrikan dan tenaga pesawat tempur.

Penggunaan twin engine menjadi prioritas utama dalam pesawat tempur generasi 5 dengan dilengkapi kemampuan supercruise dan thrust vectoring, karena secara konsep generasi 5 biasanya didesain sebagai pesawat air superiority dengan low radar cross section.

\subsection{Konfigurasi Persenjataan}

Perbedaan yang menonjol pada pesawat tempur generasi 4 dan 5 adalah peletakan senjatanya. Generasi 4 meletakkan persenjataannya pada hardpoint yang terpasang di luar, sedangkan pada generasi 5 semua senjata diletakkan di dalam fuselage, atau yang disebut dengan internal weapon bay. Pemasangan internal weapon bay dimaksudkan untuk mengurangi radar cross section.

Tabel 8. Konfigurasi pemasangan weapon pesawat tempur generasi 4 dan 5

\begin{tabular}{|l|l|}
\hline Generasi 4 dan 4+ & Generasi 5 \\
\hline External weapon bay & Internal weapon bay \\
\hline $\begin{array}{l}\text { Contoh : Eurofighter } \\
\text { Typhoon }\end{array}$ & Contoh : F-22 \\
\hline
\end{tabular}


Dalam perkembangannya, pola perang udara telah berubah, dari peperangan langsung atau dogfight beralih ke peperangan elektronika disebut dengan electronic warfare. Semakin banyak negara-negara di Dunia menyadari kenyataan terhadap keunggulan electronic warfare, terlebih dalam kebutuhan combat. Semakin besar ketergantungan pada spektrum elektromagnetik sebagai sarana komunikasi, deteksi sasaran dan pengendalian senjata. Electronic Warfare (EW) adalah tindakan yang melibatkan penggunaan spektrum elektromagnetik untuk mendeteksi, mengidentifikasi dan menganalisis data sinyal lawan yang disebut dengan electronic support measure, menghambat atau mencegah musuh dalam menggunakan spektrum elektromagnetik atau disebut dengan jamming, dan menjamin teman menggunakan spektrum elektromagnetik, serta sebagai tanda peringatan dini atau early warning.

Adanya early warning menjadi perintah kepada awak pesawat untuk segera mengaktifkan electronic counter measures dispenser yang digunakan untuk membingungkan, mengecoh atau mengelabui lawan. Contoh perangkat counter measure dispenser adalah chaff, flare, dantowed decoy. Ketiga perangkat tersebut mempunyai peran yang berbeda.

a. Chaff, lempeng metal yang dapat menimbulkan pantulan gelombang radar hingga memunculkan titik-titik target semu pada display radar lawan. Digunakan ketika ada ancaman dengan pemandu radar.

b. Flare seperti petasan yang dapat menghasilkan gelombang panas. Flare digunakan ketika ada ancaman dengan pemandu gelombang infrared.

c. Towed Decoy, seperti missile yang dapat menghasilkan gelombang radar, dilontarkan dengan menggunakan semacam kabel. Towed decoy digunakan ketika ada ancaman dengan pemandu gelombang radar.

Baik generasi 4 maupun 5, telah menggunakan electronic walfare yang dipasang pada pesawat, namun terdapat perbedaan dari segi peletakannya. Pada pesawat tempur generasi 4 dan 4+, beberapa perangkat electronic warfare masih dipasang pada pod, sedangkan pada generasi 5 semua electronic warfaresudah berupa chipdan dipasang di badan pesawat.
Pertimbangan peletakan komponen electronic warfare berdasarkan pada spesifikasi komponen, fungsi dan size komponen. Radar Warning Receiver (RWR) biasanya diletakan di sayap pesawat. Jika daya jangkau RWR $90^{\circ}$ maka RWR diletakkan di empat sisi, yaitu sayap kanan dan kiri bagian depan dan belakang. Jika daya jangkau RWR $180^{\circ}$ maka diletakkan di dua sisi sayap kanan dan kiri, dalam hal ini penulis tidak mendapatkan data derajat yang dapat dikaver oleh radar warning receiver yang ada di dunia.

Missile Warning Receiver (MWR) Bertugas untuk mendeteksi adanya sinyal infrared yang mengarah ke pesawat tempur, maka MWR dipasang di bagian belakang dekat dengan exhaust yang menjadi sumber panas terbesar, selain itu MWR juga akan dipasang di pesawat bagian depan untuk mengantisipasi datangnya musuh dari arah depan.

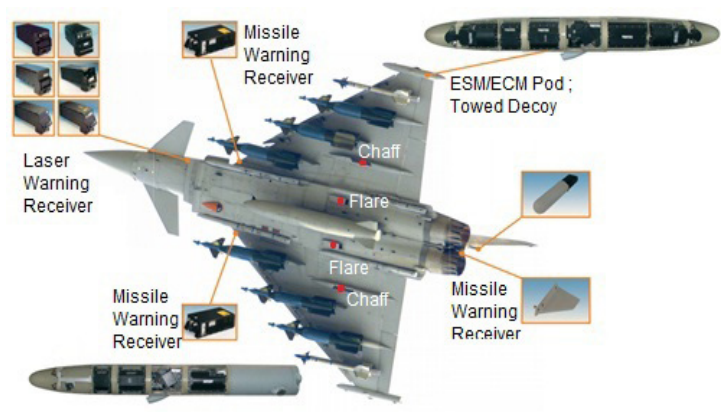

Eurofighter Typhoon

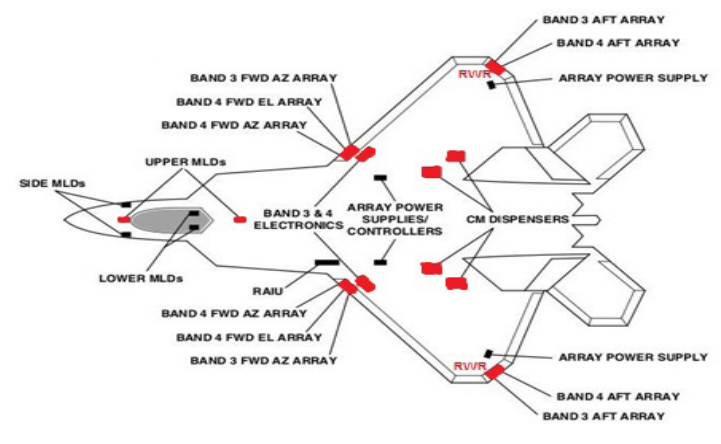

F-35

Gambar 10.Lokasi pemasangan Electronic Warfare pada pesawat tempur generasi 4 dan 5[8,9]

Jammer, umumnya dipasang di pesawat bagian depan-bawah. Pada generasi 4 dan 4+, 
jammer dipasang pada hardpoint yang menempel di pesawat. Chaff dan Flare, umumnya diletakkan di tengah badan pesawat, karena membutuhkan ruang yang cukup luas untuk meletakkan sistem electronic counter measure tersebut.

\section{Kesimpulan}

Yang menjadi unggulan pesawat tempur generasi 5 adalah konsep low Radar Cross Section (RCS), yang membuat pesawat tidak mudah untuk diidentifikasi keberadaannya oleh pesawat lain. Konsep low RCS diimplementasikan pada perancangan internal weapon bay, blended wing body, internal fuel tank, low observable inlet, dan penggunaan Radar Absorbent Material (RAM) pada material kompositnya. Konsep low RCS ini tidak mudah diterapkan pada generasi sebelumnya. Pesawat tempur generasi 4 hanya mengembangkan konsep low RCS dengan cara penggunaan RAM (Radar Absorbent Material), sehingga dapat diambil kesimpulan bahwa setiap pesawat tempur yang tidak menerapkan konsep low RCS secara menyeluruh, maka dapat dikategorikan sebagai pesawat tempur generasi 4.

\section{Saran}

Diharapkan adanya penelitian secara terperinci tentang pengaruh Radar Cross Section (RCS) berdasarkan bidang pantulnya, sehingga didapatkan konfigurasi pesawat yang tepat agar mendukung konsep low radar cross section.

Setelah mengetahui perbedaan konfigurasi pesawat tempur generasi 4 dan 5, maka untuk kedepannya diharapkan ada kajian mengenai DR \& O (Design Requirement dan Objective) atau sasaran dan tujuan yang tepat untuk merancang pesawat tempur yang dibutuhkan Indonesia, baik yang mengacu pada generasi 4 maupun generasi 5 .

\section{DAFTAR PUSTAKA}

[1] Hartmann, Frederick H., 1983, Digital Image Processing, Vol. 1, Ed.2, Prentice Hall, New Jersey.The Relations of Nations, Macmillan Publishers Limited, New York, hlm 43.

[2] PAK-FA Pictures and Videos, 2010, http:// defence.pk/threads/pak-fa-pictures-andvideos.45736/page-8.

[3] F-35 vs F-15SE :South Korea's F-X III Competition - Part II The Silent Eagle, 2013, http://manglermuldoon.blogspot. com/2013/06/f-35-vs-f-15se-south-koreasf-X-iii.html

[4] From Russia With Love, 2001, http://www. airsceneuk.org.uk/airshow01-/zhukovsky/ maks.htm

[5] Scott Jeff., 2002, Axisymmetric \& Thrust Vectoring Nozzles, Aerospace Web, http:// www.aerospaceweb.org/question/propulsion/ q0095.shtml

[6] Thrust Vectoring, 2014, http://en.wikipedia.org/ wiki/Thrust_vectoring

[7] Supercruise, 2014, http://en.wikipedia.org/wiki/ Supercruise

[8] UK Armed Forces Commentary, (2012) :Eurofighter Typhoon, http://ukarmedforcescommentary.blogspot.com/p/ eurofighter-typhoon-.html

[9] Fundamentals of Stealth Design \& Concept of RCS Reduction, http://defence-.pk/threads/ fundamentals-of-stealth-design-concepts-ofrcs-reduction.73549/page-2 
